\title{
ENSINO DE INGLÊS PARA LEITURA: OPORTUNIDADES DE APRENDIZAGEM E FOCO NO DISCURSO
}

\begin{abstract}
Isabel Cristina Rangel Moraes Bezerra é professora da UERJ, mestre em Linguística Aplicada (UFRJ), doutora em Letras (PUCRio) e pós-doutoranda (PUC-Rio). Seus interesses de pesquisa incluem discurso institucional, ensino de língua estrangeira, construção de identidade, formação e reflexão docente, produção de material de ensino.

E-mail: icmoraes@uol.com.br

Renata Lopes de Almeida Rodrigues é professora de língua inglesa da UERJ, mestre em Linguística Aplicada (UFRJ), doutoranda em Estudos da Linguagem (PUC-Rio). Seus interesses de pesquisa incluem formação de professores de línguas e questões sobre ensino e aprendizagem de língua estrangeira.

E-mail: renatalar@gmail.com.br
\end{abstract}

\section{RESUMO}

Neste estudo, refletimos sobre a produção de material para ensino de inglês em um projeto acadêmico. Problematizamos dois momentos vividos pelo grupo, reveladores das perspectivas dos participantes com relação à teorização e à montagem do material.

\begin{abstract}
In this paper, we reflect upon the production of English teaching material in an academic project. We problematize two moments lived by the group which reveal the participants' perspectives in relation to theoretical issues and material design.
\end{abstract}

\section{Introdução}

Através deste trabalho, orientadas pelo viés filosófico discursivo da Prática Exploratória, uma forma híbrida, ético-inclusiva de ensinar e refletir/investigar (Miller, 2010; Miller et al. 2008), pretendemos discutir o processo de produção de material instrucional para compreensão de textos em língua inglesa. Tal processo tem sido coconstruído na interação entre professoras-orientadoras e professores em formação inicial, bolsistas efetivos e voluntários no projeto de Iniciação à Docência (ID) Aulas $e$ material de leitura: uma perspectiva da formação docente em língua inglesa, coordenado por nós na universidade onde lecionamos - UERJ. Dada a natureza discursiva e social deste estudo, nós - professoras-orientadoras - buscamos entendimentos acerca de algumas questões que envolvem a formação desses profissionais nesse projeto de ID, como a co-construção de oportunidades de aprendizagem (Allwright, 2005) que nos ajudem a desenvolver uma consciência crítica como profissionais ou pares mais competentes nessa interação (Vygotsky, 1998).

Para analisar o processo de orientação e produção de unidades de leitura para o ensino de língua inglesa, trazemos dados provenientes de dois momentos relativos à vida do grupo (Gieve e Miller, 2006) em que tentamos mapear oportunidades de aprendizagem (Allwright, 2005). O primeiro deles trata do conteúdo de um pôster elaborado pelos bolsistas, que é fruto de sua reflexão sobre seu processo de produção de 
unidades de leitura ao longo de sua participação no projeto de ID. O segundo deles diz respeito a um fragmento da interação entre alguns dos participantes em uma de nossas reuniões. Desta forma, esperamos ilustrar e fundamentar as questões aqui apresentadas, problematizando nossa experiência de orientação de bolsistas de iniciação à docência.

\section{1) Sobre o Projeto de Iniciação à Docência}

O Projeto de Iniciação à Docência nessa universidade tem por objetivo aproximar os professores em formação inicial da prática docente a fim de que vivenciem, de alguma forma, a experiência docente durante o curso de licenciatura. Considerando nossa afinidade acadêmica com a Linguística Aplicada e a partir da perspectiva reflexiva da Prática Exploratória (Allwright, 1996a, 1996b, 1991), entendemos que o ambiente docente e/ou as atividades envolvidas na docência estão diretamente relacionadas à pesquisa. Portanto, o nosso engajamento no projeto de ID perpassa um embasamento teórico-metodológico para que a elaboração de material se torne um processo consciente, crítico e reflexivo, uma vez que procuramos estar atentos à sala de aula como um contexto de pesquisa ou um campo de investigação constante que dá lugar à curiosidade e à experiência como ferramentas da prática pedagógica. Isso significa criar uma "atitude reflexiva" (Moraes Bezerra, Miller e Cunha, 2007, p. 193) na prática de professores que ainda virão a atuar no contexto de sala de aula.

Uma vez que a elaboração de um material instrucional requer a sua implementação prática, para que essa experiência e oportunidade de reflexão seja possível, planejamos um curso de extensão anual em que esses professores em formação inicial possam desenvolver a prática pedagógica em seus diferentes estágios. Esse curso é voltado para a comunidade interna e externa da universidade. As aulas se constituem de novas oportunidades de aprendizagem (Allwright, 2005) para todos os participantes, pois, após as aulas, fazemos sessões de discussão sobre as mesmas. Nesses encontros, cada participante, havendo implementado a atividade ou não, compartilha e discute suas visões sobre as ações durante aquela experiência.

Atualmente temos dois bolsistas efetivos e três bolsistas voluntários atuando neste trabalho. Fazemos encontros semanais para a discussão de textos teóricos sobre temas relevantes para as atividades dos bolsistas, tais como produção de material, teoria sócio-histórica, Prática Exploratória, dentre outros. Da mesma forma o grupo discute e reflete sobre a proposta de cada uma das unidades de leitura por eles produzidas. Além disso, os bolsistas são encorajados a participar em eventos acadêmicos na área, seja como apresentadores de comunicações/pôsteres ou como dinamizadores de oficinas, pois consideramos tais experiências essenciais para a formação da identidade do professor-pesquisador.

\section{2) Vivendo a Prática Exploratória no projeto de Iniciação à Docência}


$\mathrm{Na}$ condição de professoras-orientadoras, partimos da perspectiva da Prática Exploratória (Allwright e Hanks, 2009; Moraes Bezerra, 2007; Miller, 2001) na construção de entendimentos sobre as nossas ações e reflexões na prática de orientação. Inspiradas pelos princípios da Prática Exploratória (PE, de agora em diante), buscamos envolver todos no processo reflexivo, uma vez que, alinhadas aos proponentes desta forma de ensinar-aprender-pesquisar, entendemos que é preciso caminhar na direção do desenvolvimento de todos os envolvidos, integrando o trabalho reflexivo às práticas de orientação do projeto, bem como às discussões sobre o material didático produzido pelos bolsistas.

Os princípios norteadores da PE são, de acordo com Miller et al. (2008, p.147):

Priorizar a qualidade de vida.

Trabalhar para entender a vida na sala de aula e em outros contextos profissionais.

Envolver todos neste trabalho.

Trabalhar para a união de todos.

Trabalhar também para o desenvolvimento mútuo.

Integrar este trabalho com as práticas de sala de aula ou com outras práticas profissionais.

Fazer com que o trabalho para o entendimento e a integração sejam contínuos.

Com esses princípios em mente, nossa maneira de conduzir a orientação acadêmica para a docência se constitui em uma tentativa de distanciamento da ideia tradicional de formação de professores como sinônimo de 'treinamento' ou ainda a orientação de que uma aula de línguas seria a apresentação e a prática de pontos ou itens linguísticos pré-definidos, no que diz respeito aos objetivos dos professores (Allwright, 2005). A postura reflexiva (Miller et al. 2008) que adotamos e que desenvolvemos com os bolsistas em relação à prática docente é parte integrante de nosso trabalho de orientadoras. Isso faz com que estejamos atentas ao que acontece conosco durante nossas reuniões, a cada encontro. Fazemos isso pensando que o ensinar e o aprender estão relacionados ao planejamento a fim de "oferecer riquezas de oportunidades e especialmente para entender" (Allwright, 2005, p. 10).

Para os professores em formação inicial, o contato com a PE os ajuda a "desenvolver o seu entendimento da vida na sala de aula" (Miller et al. 2008, p. 146) e além da sala de aula. Dessa forma, nos tornamos todos agentes nesse processo (Moraes Bezerra, Miller e Cunha, 2007), somos praticantes trabalhando para o desenvolvimento de todos, a partir dos entendimentos ali construídos em conjunto.

\section{1) O trabalho para entender e a qualidade de vida}

Através da PE (Allwright, 1999, 1996a, 1991), os praticantes em um determinado grupo buscam envolver-se em um trabalho contínuo para entender as questões que perpassam as relações interpessoais, o trabalho desenvolvido pelo grupo, 
bem como qualquer questão positiva ou não que tenha reflexos sobre a vida do grupo. Na verdade, Allwright e Miller (2002) já apontavam a PE como um caminho importante para a tentativa de se compreender a vida, não apenas em sala de aula, como também em qualquer contexto social, já que a vida está lá, fazendo parte do contexto pedagógico ou profissional. Ela, portanto, não pode ser ignorada, mas reconhecida pelas implicações que traz para a qualidade de vida do grupo (Gieve e Miller, 2006; Moraes Bezerra, 2010). Esta é entendida como processo, como algo que está em constante configuração, sendo influenciada pelas posições institucionais e discursivas dos participantes, da mesma forma que é influenciada por suas ações discursivas. Sublinhamos que a qualidade de vida em um dado contexto pode dimensionar um espaço de inserção colaborativa ou de exclusão dos participantes.

Além disso, a qualidade de vida é o que aprendizes e professores entendem, ou buscam entender, sobre suas experiências em sala de aula (Gieve e Miller, 2006, p.23). Da mesma forma, acreditamos que isto aconteça com professores orientadores e bolsistas, professores e consultores, por exemplo, em suas práticas reflexivas profissionais, a partir do arcabouço da PE. Acreditamos que a qualidade de vida, relacionada à qualidade das relações interpessoais discursivamente construídas no e pelo grupo de praticantes, envolve questões afetivas que, por sua vez, refletem-se de maneira mais ou menos positiva nas experiências de ensinar, aprender, planejar, orientar, ser orientado. Decorre daí que a qualidade de vida não é algo a ser mensurado, mas diz respeito à natureza daquelas relações e como os praticantes lidam com ela.

É importante destacar também que a qualidade de vida à qual nos referimos não está ligada à qualidade do ensino (Allwright, 2006) centrada no professor. A busca conjunta de entendimentos em contextos educacionais leva à reflexão sobre esse aspecto central do processo de ensino/aprendizagem, que vai além da eficácia de procedimentos pedagógicos, pois envolve também as relações afetivas que são construídas nesses ambientes. Segundo Allwright e Hanks (2009, p.150), a qualidade de vida é "altamente complexa e difícil de ser capturada". No entanto, acreditamos que podemos perceber sua configuração através das ações discursivas dos participantes nas interações em que se engajam.

Na perspectiva da PE, é possível que a dinâmica do processo coletivo de construção de entendimentos sobre a ação docente ou discente e que configuram a qualidade da vida no grupo seja conduzida por puzzles. Estes são questões que emergem do estar cotidiano em contextos diversos e que levam os participantes a debruçarem-se sobre tais questões. Podem ser questões como: Por que meus alunos não se envolvem nos projetos da escola? Por que minhas colegas engravidam tão cedo? (puzzle de uma aluna do ensino médio).

Por outro lado, a reflexão através da PE pode ser conduzida sem que haja um puzzle definido, mas através de uma atitude exploratória que favoreça a construção de um olhar mais cuidadoso às práticas sociais e discursivas ainda quando estas estão em 
construção nas interações. Este olhar pode ser aprofundado a partir da análise de registro de atividades, relatos, pôsteres e transcrições.

Desta forma, nos encontros com os bolsistas, trabalhamos na tentativa de construir não só conhecimento teórico e prático sobre a produção de material de leitura, mas também com o intuito de aproveitarmos as oportunidades de aprendizagem (Allwright, 2005) que se apresentam a partir de nossas interações com o grupo, o que nos leva à reflexão crítica sobre nosso fazer profissional neste contexto de atuação. Durante nossas reuniões de orientação, durante a preparação de trabalhos acadêmicos para apresentação em eventos da área ou durante a preparação e implementação do curso de extensão para a comunidade sobre compreensão escrita em língua inglesa, desenvolvemos, em conjunto, um ambiente reflexivo constante.

Com isso, buscamos entendimentos sobre as questões que emergem da nossa experiência docente a partir da reflexão conjunta, com a finalidade de envolver todos nesse processo de entendimento, professoras-orientadoras e bolsistas. Enfatizamos que nosso papel de orientadoras tem sido ressignificado à medida que refletimos sobre nossas ações.

Vivemos as orientações como um canteiro fértil de oportunidades de aprendizagem e de complexidades, de geração de entendimentos. Segue-se que nos vemos como um conjunto de atores sociais com papel ativo no processo de coconstrução de sentidos. A pesquisa, portanto, permeia os encontros e cada um de nós, professoras-orientadoras e licenciandos, assumimos o papel de praticantes exploratórios. Allwright e Hanks (2009) veem os alunos também como praticantes, pois esses desempenham papel central na prática, no processo de ensino/aprendizagem de línguas. Portanto, assumimos uma postura exploratória que prioriza a qualidade de vida do grupo e o desenvolvimento de todos.

\section{2) Oportunidades de aprendizagem, afeto e a orientação dos bolsistas}

Tomando por foco a sala de aula, Allwright (2005) propôs, baseado em Grabbe (2003), a noção de 'oportunidades de aprendizagem'. Elas seriam situações que podem conduzir à socioconstrução de conhecimentos não apenas na dimensão cognitiva, mas também nas dimensões afetiva, social e subjetiva. Tais oportunidades podem surgir na interação sem que sejam necessariamente provocadas pelos participantes. Por outro lado, são difíceis de planejar ou de produzir, especialmente se pensarmos nas peculiaridades de cada aluno e no nível de conhecimento real que cada aprendiz haja atingido (Vygotsky, 1998). Considerando a aprendizagem a partir da perspectiva teorizada por Vygotsky, entendemos que a construção de conhecimentos - situada social, cultural e historicamente - está relacionada a experiências de aprendizagem significativas por envolverem o aspecto afetivo do aprendiz. Consequentemente, também esse aspecto interfere e dimensiona a forma como a internalização do conhecimento acontece, ou seja, como o nível de desenvolvimento potencial 
transforma-se em desenvolvimento real. Assim, as oportunidades de aprendizagem, se aproveitadas pelos praticantes, podem configurar esse processo de aprender e igualmente agregar dimensões afetivas significativas para o aprendiz, construindo-se, assim, andaimes emocionais (Emotional scaffolding, Rosiek, 2004). Nesta linha de pensamento, entendemos que a experiência de aprendizagem é, acima de tudo, uma experiência humana e toda experiência humana é, para Rosiek (2004), um caso emocional, que envolve prazer, surpresa, curiosidade.

A condução do processo de ensinar-aprender, orientar-produzir, ou qualquer outro - em que os atores sociais envolvidos configurem pares em que haja o mais competente e o menos competente - considerando as oportunidades de aprendizagem, "leva os participantes da situação a ficarem mais atentos, a aguçarem o olhar, o ouvir e o sentir do que acontece enquanto está acontecendo" (Miller et al. 2008). Essa simultaneidade configura a vida na sala de aula, que não pode ser dissociada da vida fora desta. Ao passarem pelo período de formação, os futuros professores precisam refletir sobre essas questões. Eles precisam pensar o seu contexto de trabalho como um lugar onde se trabalha com a experiência humana, no qual é preciso "entender a emoção do aluno" (Rosiek, 2004, p. 400).

Considerando-se, portanto, as questões apontadas, encontramos justificativa para o trabalho reflexivo que desenvolvemos no projeto de ID, o qual tentamos registrar no presente artigo, em especial a partir da próxima seção, através das análises e interpretações que propomos. Trata-se de uma tentativa de partilhar um estar colaborativo no espaço de formação docente atentando não apenas para a instância cognitiva de construção de conhecimento, mas também reconhecendo o lugar da emoção e do espaço de acolhimento para o questionamento da prática docente inicial (dos bolsistas) e continuada (das orientadoras).

\section{3) Por que a reflexão crítica sobre o material que produzimos cria oportunidades de aprendizagem para os participantes do projeto de ID?}

O título desta seção é o puzzle que conduz nosso olhar de praticantes exploratórias ao olharmos reflexivamente para uma prática docente já instalada há algum tempo. Nosso objetivo é resgatar, dos elementos discursivos que serão foco de nossa análise, possíveis oportunidades de aprendizagem e entendimentos sobre este processo. Numa tentativa de mapear essas questões, buscaremos tratar também um pouco da qualidade de vida do grupo. Assim, problematizamos:

[a] os puzzles e os entendimentos dos bolsistas registrados no pôster que planejaram e produziram para ser apresentado no evento anual de Prática Exploratória, conforme detalhamento apresentado na seção 3.1;

[b] nossa interação discursiva presente no fragmento transcrito de uma reunião 
do grupo.

\section{1) O pôster: refletindo criticamente sobre a prática de produção de material e} sobre o ensino

Embora o viés reflexivo da PE seja uma constante no projeto de ID, no evento anual de Prática Exploratória que acontece na PUC-Rio, nossos bolsistas Thami, Dani, Felício e Rod tiveram a oportunidade de problematizar o seu percurso de produtores de material didático. Em conjunto, formularam os seguintes puzzles, presentes no pôster que apresentaram no evento e cuja foto encontra-se na página seguinte. Vale ainda observar o título que deram a ele, pois reflete um momento bem marcado de seu percurso no projeto: a construção de suas identidades de professores de inglês face às dificuldades que enfrentavam.

Questionando nosso processo de produção de material de leitura em língua inglesa: entendendo nossas dificuldades.

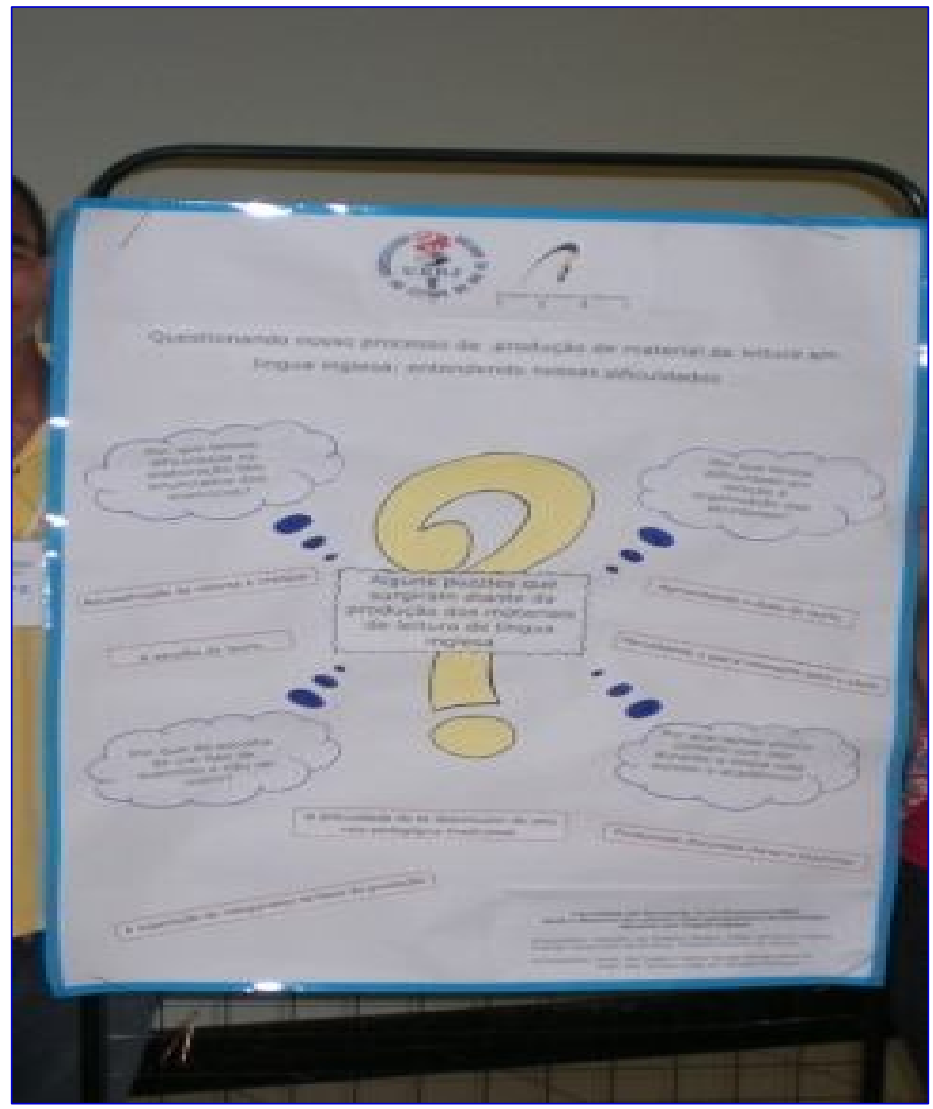


1. Por que temos dificuldades na elaboração do enunciado dos exercícios?

2. Por que da escolha de um tipo de exercício e não de outro?

3. Por que temos dificuldades em relação à organização das atividades?

4. Por que temos pouco contato com isto durante nossa vida escolar e acadêmica?

Tais puzzles remetem à dificuldade que os bolsistas sentiam naquele momento ao produzirem unidades de leitura. O primeiro deles aponta para a dificuldade de construírem enunciados que dessem conta de informar ao aluno leitor as instruções exatas para a realização da atividade. Tal questionamento surgiu quando perceberam, durante as reuniões do grupo para apresentação e discussão das unidades, que nem sempre ficava claro para os colegas ou para as professoras o que se esperava que fosse feito pelos alunos quando estes tentassem responder as atividades cujos enunciados haviam sido produzidos pelo(s) autor(es) da unidade de leitura.

O segundo puzzle reflete a dificuldade de os bolsistas formularem exercícios que demandassem do aprendiz alguma ação além de correlacionarem colunas ou marcarem uma resposta em exercícios de múltipla escolha ou ainda a identificarem a afirmações falsas ou verdadeiras em relação ao texto da unidade. Na verdade, os bolsistas de ID verificaram que as atividades por eles propostas tinham o mesmo formato das atividades que haviam vivenciado enquanto alunos de inglês no ensino fundamental e médio. Acreditamos que esse puzzle articula-se ao primeiro na medida em que, ao tentarem sair do padrão de exercícios com o qual estavam acostumados, os bolsistas não conseguiam elaborar enunciados claros para atividades diferentes.

O terceiro puzzle diz respeito à dificuldade que sentiam em organizar sequências de atividades que pudessem ser alocadas nas etapas de pré-leitura, leitura e pós-leitura, conforme sugerem os proponentes dos PCN-LE (1998). Talvez ainda operassem a partir de uma rigidez quanto ao tipo de atividade que poderia/deveria ser alocada em cada uma delas, não percebendo que é possível usar a criatividade e desafiar o aluno leitor.

Já o quarto puzzle traz um questionamento que remete ao fato de os bolsistas não haverem vivenciado uma proposta pedagógica sobre o processo de ensinar-aprender, bem como sobre a produção de material didático, que se alinhasse às diretrizes que encontraram no projeto de ID, seja enquanto alunos de ensino fundamental/médio, seja enquanto licenciandos de Letras antes de tornarem-se bolsistas do projeto. Quanto aos possíveis entendimentos, que propuseram no pôster, temos:

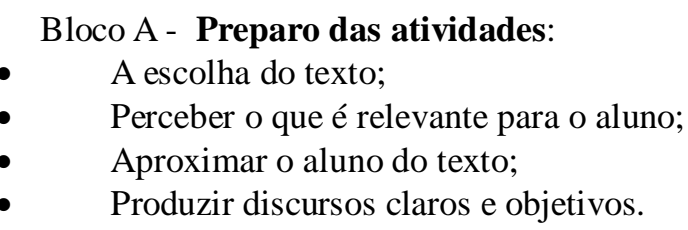

O bloco A de entendimentos registrados no pôster está mais voltado para o planejamento e preparo das unidades, podendo ser identificados através dos seguintes 
fragmentos: escolha do texto, relevante para o aluno, discursos claros e objetivos. Vemos a preocupação dos bolsistas com a seleção do texto atrelada à possível relevância que a temática deste possa ter para a vida do aluno. Em seguida, ao colocarem 'aproximar o aluno do texto' parecem estar refletindo sobre a importância de proporem atividades que contribuíssem para o envolvimento do aluno no texto desde a pré-leitura, como é sublinhado nos PCN-LE (BRASIL, 1998). Finalmente, quanto à redação dos enunciados, os bolsistas remetem à necessidade de os redigirem de forma mais clara $\mathrm{e}$ objetiva. Tais entendimentos parecem refletir a base teórica que fundamenta a proposta de formação docente contida no projeto de ID que coordenamos. Ademais, essa forma colaborativa de refletir propiciada pela configuração de 'agir para entender' da PE trouxe para o primeiro plano questões de importância para a educação inicial daqueles alunos-professores.

No mesmo pôster os bolsistas registraram um segundo bloco de entendimentos:

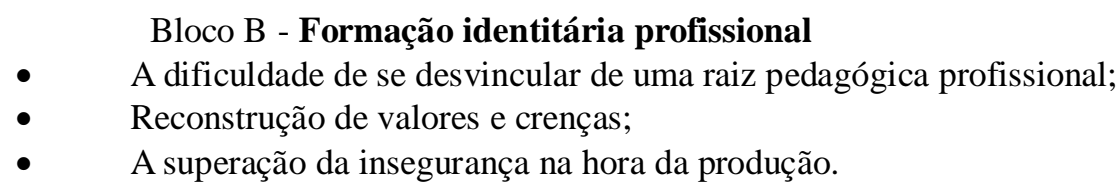

Já o bloco B parece revelar uma tensão entre ser aluno e ser professor em formação no processo de construção identitária através das práticas discursivas (Moita Lopes, 2002; Moraes Bezerra, 2007) no projeto de ID. Eles tiveram que identificar algumas crenças trazidas para o processo as quais foram colocadas em xeque em face das teorias e práticas docentes que formam a moldura que conduz a proposta do projeto. Ademais, tiveram que construir um olhar reflexivo, nessa 'oportunidade de aprendizagem' (Allwright, 2005), ao aspecto afetivo-subjetivo presente na necessidade de 'superação da insegurança na hora da produção'. Ou seja, era preciso superar o 'medo de errar', passando a ver o erro como indício do processo de construção de conhecimentos.

Tomamos ainda como referência a teorização vygotskyana (Vygotsky, 1998, 1987) sobre aprendizagem para analisar essas questões: os entendimentos também apontam para o inter-relacionamento entre os planos intra e intersubjetivos no processo de construção dos entendimentos. Consideramos, por exemplo, que a "reconstrução de valores e crenças" só pôde acontecer não apenas pelo contato com a nova base teórica representada pelos textos lidos no projeto. Ela aconteceu fundamentalmente através do processo interacional e dialógico de discussão coletiva do material produzido pelo grupo ao refletirem sobre as dificuldades encontradas para a produção de material didático para leitura. Ademais, ao mencionarem 'A dificuldade de se desvincular de uma raiz pedagógica profissional' remete a uma dimensão cultural que, de certa forma, produz modos de fazer pedagógico que se cristalizam ao longo do tempo. Por outro lado, a questão afetiva presente no processo de ensinar-aprender, além daquelas

Rua Marquês de São Vicente, 225 Gávea/RJ CEP 22453-900 Brasil

Ano 2012. Número 15. ISSN 1679-6888.

escrita@puc-rio.br 
referentes aos campos cognitivo e social, está presente e não pode ser considerada como coisa menor, uma vez que sua indelével presença faz marcas mais ou menos profundas na memória sobre aprendizagem do aprendiz. Assim, a produção do pôster configuravase como uma 'oportunidade de aprendizagem', permitindo aos praticantes exploratórios, em seu processo formativo, mapear e analisar crenças trazidas, trabalhar para a sua reconstrução à luz das práticas discursivas e proposta teórica que encontraram no projeto. Do mesmo modo, envolveram-se não apenas na ação coletiva de aprender, mas envolveram-se, da mesma forma, na ação reflexiva de entender o processo formativo que vivenciavam no tocante a contradições/ problemas, conforme registrado em seus puzzles, e a ganhos registrados nos 'entendimentos'.

Assim sendo, a atividade de identificação de puzzles com os quais os bolsistas possivelmente conviviam de maneira não consciente, bem como o trabalho para construir entendimentos a partir dos mesmos, parece ter possibilitado:

[a] identificar e problematizar crenças, valores e modelos de prática docentes trazidos para sua formação no contexto universitário;

[b] decidir se havia ou não a necessidade de rever e reconstruir os valores e crenças trazidos, sem que tal ação para mudar se configurasse como uma demanda das orientadoras;

[c] perceber dificuldades no processo de produção de atividades para as unidades de leitura;

[d] considerar a importância do aprendiz e de seus interesses e desejos ao planejarem e produzirem uma unidade de leitura;

[e] estabelecer uma relação entre, bem como problematizar, a vivência de ser aluno de um curso de formação de professor e de ser bolsista de um projeto de ID, mapeando e refletindo sobre as contradições com as quais se depararam.

\section{2) A reunião}

Nesta seção, trazemos uma microcena transcrita de uma interação no projeto de ID (convenções para a transcrição no apêndice). Para construir a análise da interação, usamos construtos vindos da análise da conversa: turnos, sobreposição de turnos, alongamento de vogal, engatamento de turno; e da sociolinguística interacional: alinhamento (Goffman, 2002).

Essa interação acontece após havermos discutido um capítulo de um dos livros de Vygotsky. Cabe ressaltar que nós, coordenadoras do projeto, costumamos planejar, quase sempre com a colaboração dos bolsistas, a dinâmica das reuniões, o agendamento 
de tarefas, as leituras. Na microcena abaixo, porém, a professora Isabel passa a fazer algo que não havia sido combinado com a professora Renata nem com os licenciandos: questionar os bolsistas sobre como conseguiam articular a teoria vygotskyana às atividades do projeto e, em especial, à produção de unidades de leitura. Acreditamos que essa ação possa ser vista como o aproveitamento de uma 'oportunidade de aprendizagem' trazida pela discussão do texto no grupo naquele momento.

Data: $12 / \mathrm{maio} / 2010$

Presentes: professoras coordenadoras (Isabel [Isa] e Renata [re]) e os bolsistas (Thami, Rod e Rosi) Microcena: Articulando o texto de Vygotsky à prática no projeto de ID

\begin{tabular}{|c|c|c|}
\hline Isa & 1 & Então o que eu quero que vocês me digam= \\
\hline $\operatorname{Re}$ & 2 & $=\underline{0} \operatorname{sim}$, senhora $0=$ \\
\hline Isa & $\begin{array}{l}3 \\
4 \\
5 \\
6 \\
7 \\
8\end{array}$ & $\begin{array}{l}\text { = qual a relação que vocês veem nisso com a proposta do projeto?(.) que } \\
\text { link vocês conseguem fazer porque aqui "ah, mas tá falando muito da } \\
\text { criança e tal" mas tudo bem é a base da teorização de Vygotsky que a } \\
\text { gente- tem estudiosos que estão ampliando isso obviamente até pro } \\
\text { adulto, né? então como é que a gente pode fazer o link entre isso e o que } \\
\text { a gente faz aqui? porque de estudar isso, enfim. }\end{array}$ \\
\hline Thami & $\begin{array}{c}9 \\
10 \\
11 \\
12\end{array}$ & $\begin{array}{l}\text { partindo da nossa prática que a gente: a gente produz o material e é } \\
\text { depois a gente discute em grupo eu acho que tá refletindo aí essa teoria } \\
\text { do Vygotsky do: a: dos pares mais competentes e: da do } \\
\text { interdiscurso. porque a gente constrói isso na nossa prática. }\end{array}$ \\
\hline Isa & $\begin{array}{l}13 \\
14\end{array}$ & $\begin{array}{l}\text { e pra a produção do material mesmo? Como vc pode usar isso aí como } \\
\text { aporte no momento em que você vai preparar uma unidade de leitura? }\end{array}$ \\
\hline Thami & $\begin{array}{l}15 \\
16 \\
17 \\
18 \\
19 \\
20 \\
21\end{array}$ & $\begin{array}{l}\text { ah sim, principalmente porque a nossa unidade de leitura ela é sempre } \\
\text { voltada muito a:: a reflexão, a buscar essa reflexão do aluno, a: a: } \\
\text { professor, entendendo o professor como mediador do aluno: em } \\
\text { hã:: e o texto então: (.) a gente sempre trabalha não co: } m \text { tradução mas } \\
\text { buscando que o aluno: entenda: aquela: todos os conhecimentos } \\
\text { sistêmico, organizacional e tal através é: da reflexão mediada pelas nossas } \\
\text { questões que a gente coloca ali nos enunciados que a gente produz. }\end{array}$ \\
\hline Rosi & $\begin{array}{l}22 \\
23\end{array}$ & $\begin{array}{l}\text { Olevar em consideração os aspectos sociais, culturais na produção desse } \\
\text { material né didático. } \underline{ }\end{array}$ \\
\hline Rod & $\begin{array}{l}24 \\
25 \\
26 \\
27 \\
28 \\
29 \\
30 \\
31\end{array}$ & $\begin{array}{l}\text { é eu acho que eu concordo ( ) com o que a Thami falou que a gente } \\
\text { tá produzindo e sempre pensando no outro né? então a gente tá: } \\
\text { acho que fazendo esse papel mesmo quando a gente tá sozinho em casa } \\
\text { fazendo a atividade, pensando como que a gente vai fazer essa } \\
\text { mediação- como que o o: a atividade que a gente tá fazendo tá } \\
\text { (favorecendo) essa mediação aqui, a nossa fala né com o aluno. e acho } \\
\text { que isso tem a ver muito a ver com o que a gente tá lendo aqui sobre } \\
\text { Vygotsky. }\end{array}$ \\
\hline
\end{tabular}

Nas linhas 3 a 8 é possível ver a solicitação de Isa: articular a teorização vygotskiana ao projeto de ID. Na verdade não há um engajamento imediato na construção da resposta, pois após a pergunta inicial, há o abaixamento de voz, uma breve pausa (linha 3) sem que nenhum dos participantes tome o turno para responder a questão. Isso faz com que Isa tenha que reformular sua questão, explicando-a novamente. 
Na medida em que os participantes se envolvem, há um processo discursivo de construção de oportunidade de aprendizagem para todos. Os dois turnos de Thami mostram um esforço discursivo para fazer o que fora solicitado. No nível do micro discurso é possível detectar o processo de elaboração de entendimentos acontecendo. Tal processo é evidenciado nos dados a partir dos elementos em negrito na transcrição e destacados:

[a] hesitações e alongamento de vogal - linhas 11 e 16 a 20

[b] pausa - linha 18

[c] repetições - linha 17

É possível ainda identificar, ao longo da participação de Thami, a utilização de construtos de sua área de formação pela seleção lexical que faz: 'pares mais competentes, interdiscurso, mediador, conhecimento sistêmico'. Nesse momento da interação revela-se um processo de apropriação de conceitos da área de atuação profissional que consideramos entendimentos em construção.

Ressaltamos na participação de Rosi - linhas 22 e 23 - sua colaboração para explicitar como via a articulação da teorização ao trabalho de produção de material de leitura. Ela lembra a necessidade de se articular o material produzido ao próprio contexto sociocultural no qual o mesmo será implementado. É uma forma de indicar e talvez criticar o material didático produzido que tenta dar conta das necessidades e interesses de qualquer aluno em qualquer lugar.

Finalmente, a participação de Rod mostra que ele se alinha à colega -eu acho que eu concordo ( ) com Thami (linha 24) - partindo do que ela havia sinalizado para aprofundar a explicação. Rod aponta que é preciso pensar no aluno a quem o material de leitura se destina e como fazer tal mediação através das atividades - pensando como que a gente vai fazer essa mediação (linha 27). Esse fragmento remete a entendimentos aos quais chegaram sobre as suas questões de elaboração de atividades contidas no pôster e analisadas na seção anterior: 'perceber o que é relevante para o aluno' e 'aproximar o aluno do texto'. Acreditamos que tal fragmento da mesma forma mostre a apropriação de um construto presente na teorização vygotskiana.

Ressaltamos assim, através da análise da interação, o processo de socioconstrução de conhecimentos e de entendimentos, mediado pela linguagem, conforme teorizado por Vygotsky. É o mapeamento de um momento em que ocorre microgênese de conhecimentos. Destacamos, ainda, a colaboração e o alinhamento entre os discursos dos participantes como um elemento que os integra no processo de formação, eles se alinham teoricamente e buscam entendimentos em conjunto sobre as questões que se referem à prática. Por exemplo, nas falas abaixo:

[1] Thami: "porque a nossa unidade de leitura ela é sempre voltada muito a:: a reflexão" 
[2] Rosi: "levar em consideração os aspectos sociais, culturais na produção desse material didático".

[3] Rod: "é eu acho que eu concordo ( ) com o que a Thami falou que a gente tá produzindo e sempre pensando no outro né?"

Thami utiliza um pronome que se refere à primeira pessoa do plural, assumindo o material como uma produção em conjunto, realizada colaborativamente. No turno de Rod identificamos a utilização de ' a gente' com o mesmo fim e enfatizando que o aprendiz a quem o material se destina não é esquecido [o outro]. Rosi, embora não use, nesse trecho, o mesmo pronome ou expressão usados pelos colegas, reforça seu entendimento sobre a teoria que fundamenta o material produzido, que considera os aspectos sociocultural e histórico. Rosi resgata a referência a essa teoria feita por Thami (sempre voltada muito $a::$ a reflexão) e Rod também contribui para esse entendimento e alinhamento teórico ("a gente tá produzindo e sempre pensando no outro").

No dia em que essa interação aconteceu, o grupo havia combinado que a reunião teria um momento de discussão do texto e outro em que discutiríamos as unidades de leitura em construção. Thami, desde o começo, havia se mostrado mais interessada que a segunda parte se iniciasse, pois estava ansiosa para mostrar ao grupo a unidade que havia produzido. Esta lhe dera trabalho, mas também muito prazer, durante a elaboração. Antes da microcena acima, ela havia perguntado a hora a Rod e vimos que não teríamos tempo de fazer a discussão sobre as atividades. A professora Isa pedira que ela esperasse um pouco e fez a proposta já apontada acima. A microcena abaixo faz parte da mesma reunião e é sequência da microcena 1.

Microcena 2: Explicando o porquê

\begin{tabular}{|c|c|l|}
\hline Isa & 1 & $\begin{array}{l}\text { isso, vai. desculpe eu ter parado mas eu acho - é isso que eu queria } \\
\text { entendeu? porque parece- senão parece uns construtos assim que estão } \\
\text { voando e a gente tem que começar a atrelar ao que a gente faz. }=\end{array}$ \\
\hline Thami & 4 & $=$ humhum $=$ \\
\hline Isa & 5 & $=$ até porque isso é uma maneira de você: = \\
\hline Re & 6 & $=$ eu acho bom também= \\
\hline Isa & 7 & $\begin{array}{l}\text { = account for what you are doing tá? senão parece que tudo o que a } \\
\text { gente leu não tem nenhuma relação com o que a gente tá fazendo. }\end{array}$ \\
\hline
\end{tabular}

Após alguns turnos em que os outros participantes engajam-se na construção de entendimentos, Isa pede desculpas a todos e, em especial, a Thami, por não ter procedido conforme o combinado e explica o porquê (ver trechos em negrito). Para ela, este momento era necessário a fim de fazer a passagem entre a discussão do texto e a discussão das atividades de forma significativa. Essa atitude parece ainda revelar, ao menos naquele momento, um cuidado com os outros praticantes, propiciando o estabelecimento de uma relação de afeto positivo e gerando o estabelecimento de relações interpessoais que tem influência importante para a qualidade de vida do grupo. 
$\mathrm{Na}$ linha 4, observa-se a aquiescência de Thami e, na linha 6, o alinhamento de Re, também orientadora do projeto. Nesse momento da interação, acreditamos poder apontar que Isa mostra sua preocupação em envolver todos no processo de desenvolvimento e crescimento. Tal atitude, aliada à explicação do porquê de haver agido como fizera, pode ter implicações positivas para a qualidade de vida do grupo, na medida em que apresenta razões para sua ação que ela não fazia parte da agenda anteriormente combinada com o grupo. Na linha 6, o engatamento do turno de Renata ao de Isa bem como o conteúdo do turno parecem denotar um alinhamento à colega no sentido de aproveitar aquele momento para remeter as questões do texto que se estudava à prática.

Enfatizamos ainda que, ao analisarmos a interação, acontece outra oportunidade de aprendizagem para nós, analistas do discurso, ao focarmos em nossa ação discursiva e não apenas nas ações discursivas dos bolsistas. Na verdade, embora o trabalho para entender, em nosso caso, envolva o monitoramento de atividades de ensinoaprendizagem/orientação, enquanto estas se desenvolvem, o olhar à posteriori à interação no momento de produção de nossas ações discursivas ajuda-nos a construirmos entendimentos mais profundos acerca do que fazemos, conforme já sublinhado por Moraes Bezerra (2007).

Enquanto professoras formadoras, resgatar do discurso índices de como o processo de orientação dos bolsistas se configura, como as identidades de todos são construídas, quais elementos das teorias estudadas no processo parecem ter sido internalizado (Vygotsky, 1998) pelos bolsistas através das práticas discursivas tem sido fundamental para nossa formação profissional. Assim, cada momento nos deparamos com oportunidades de aprendizagem (Allwright, 2005) através da ação reflexiva, seja durante o processo de orientação em si, seja na construção de mais entendimentos quando retomamos interações transcritas, seja ao revisitarmos o produto do fazer docente pré-serviço de nossos bolsistas (pôsteres, unidades de leitura, relatórios, dentre outros).

\section{4) Considerações finais: orientar é uma via de mão dupla}

Os trechos apresentados ilustram apenas uma parte de todo o processo de coconstrução de entendimentos que temos vivenciado no projeto de ID até o momento. Consideramos este espaço como um contexto que foge da ideia de seguir uma lista de conteúdos para serem aprendidos, pois voltamos o nosso foco para as oportunidades de aprendizagem que surgem para todos os praticantes, nas conversas, nas orientações, na produção de material, nas participações em eventos.

Outra questão que podemos destacar como fundamental nesse contexto é a relação intrínseca entre o que fazemos em termos acadêmicos e profissionais e a experiência de vida permeada pela emoção que caracteriza esse processo de formação

Revista Escrita

Rua Marquês de São Vicente, 225 Gávea/RJ CEP 22453-900 Brasil

Ano 2012. Número 15. ISSN 1679-6888.

escrita@puc-rio.br 
de professores. Afinal, será que apenas os bolsistas precisam trabalhar para a 'superação da insegurança'? Entendendo o processo de ensinar e de orientar como uma via de mão dupla, nós aprendemos com eles.

Podemos ressaltar que ficamos mais conscientes sobre nosso fazer profissional, sobre as implicações de nossas decisões e ações discursivas, uma vez que buscamos a reflexão sobre essas ações, colaborativamente. O viés reflexivo da Prática Exploratória nos ajuda a pensar em formas diferentes de construir entendimentos sobre a nossa prática, ou seja, nossa vida no contexto educacional.

\section{Bibliografia}

ALLWRIGHT, Dick. "Epilogue". ALLWRIGHT, Dick; BAILEY, Katherine. Focus on the Language Classroom. Cambridge: Cambridge University Press, 1991.

ALLWRIGHT, Dick. Making sense of life in the language classroom. England: Lancaster University, 1996a, handout.

ALLWRIGHT, Dick. Integrating training and development: the role of research. Turkey: International Conference on Teacher Training and Teacher Development: Integration and Diversity, 1996b, handout.

ALLWRIGHT, Dick. Three major processes of teacher development and the appropriate design criteria for developing and using them. Minneapolis: University of Minnesota, 1999, handout.

ALLWRIGHT, Dick. "From teaching points to learning opportunities and beyond". In: TESOL Quarterly, 39, 2005.

ALLWRIGHT, Dick; HANKS, Judith. The Developing Language Learner - An Introduction to Exploratory Practice. London, New York: Pallgrave Macmillan, 2009.

ALLWRIGHT, Dick; MILLER, Inés Kayon. Working to understand classroom life through Exploratory Practice. Lancaster: EP Center, 2002, handout.

GIEVE, Simon; MILLER, Inés Kayon de. "What Do We Mean by 'Quality of Classroom Life'?" In: GIEVE, Simon; MILLER, Inés Kayon de. (Eds.) Understanding the Language Classroom. Hampshire: Palgrave Macmillan, 2006.

GOFFMAN, Erving. "Footing". In: RIBEIRO, B. T \& GARCEZ, P. M. (org.) Sociolinguística Interacional. São Paulo: Edições Loyola, 2002. 
GRABBE, D. "The quality of language learning opportunities. In: TESOL Quarterly 37, 2003.

MILLER, MILLER, Inés Kayon de; BARRETO, Beatriz.; KUSCHNIR, Adriana.; SETTE, Maria de Lourdes; MORAES BEZERRA, Isabel Cristina Rangel; CUNHA, Maria Isabel de Azevedo; BRAGA, Walewska. "Prática Exploratória: questões e desafios." In: GIL, Glória. E VIEIRA-ABRAHÃO, Maria Helena Educação de professores de línguas: os desafios do formador. Campinas, SP: Pontes, 2008.

MILLER, Inés Kayon de. "Construindo parcerias universidade-escola: caminhos éticos e questões crítico-reflexivas". In: GIMENEZ, Telma \& MONTEIRO, Maria Cristina Góes (Orgs.). Formação de professores de línguas na América Latina e transformação social. São Paulo: Pontes Editores, 2010.

MOITA LOPES, Luiz Paulo da. Identidades Fragmentadas. Campinas: Mercado de Letras, 2002.

MORAES BEZERRA, Isabel Cristina Rangel. "“We could be in touch with real class interaction": profissionais em formação em sala de aula de língua inglesa." In: Revista Pesquisas em Discurso Pedagógico, n.1, 2010. Disponível em: (http://www.maxwell.lambda.ele.puc-rio.br).

MORAES BEZERRA, Isabel Cristina Rangel. "Com quantos fios se tece uma reflexão?" narrativas e argumentações no tear da interação. Rio de Janeiro: Departamento de Letras, PUC-Rio, Tese de Doutorado, 2007.

MORAES BEZERRA, Isabel Cristina Rangel. MILLER, Inés Kayon de; CUNHA, Maria Isabel de Azevedo. "Prática de Ensino e Prática Exploratória: oportunidades para buscar compreender a vida no cotidiano escolar." In: FONTOURA, Helena Amaral da (org.). Diálogos em formação de professores: pesquisas e práticas. Niterói: Intertexto, 2007.

Parâmetros Curriculares Nacionais - Língua Estrangeira: terceiro e quarto ciclos do ensino fundamental. Secretaria de Educação Fundamental. Brasília: MEC/SEF, 1998.

ROSIEK, Jerry. "Emotional scaffolding: an exploration of the teacher knowledge at the intersection of student emotion and the subject matter." In: Journal of Teacher Education, vol.54, Nov./Dec., 2003.

VYGOTSKY, Lev Semyonovitch. A Formação Social da Mente. São Paulo: Martins Fontes, 1998.

VYGOTSKY, Lev Semyonovitch. The Collected Works of L. S. Vygotsky (vol. 1 Problems of General Psychology). New York, Plenum Press, 1987.

ANEXO

Revista Escrita 
Convenções de transcrição (baseado em Jefferson, de acordo com Loder e Jung, 2008)

\begin{tabular}{|l|l|}
\hline . (ponto final) & Entonação descendente \\
\hline$?$ (ponto de interrogação) & Entonação ascendente \\
\hline , (vírgula) & Entonação intermediária \\
\hline : (dois pontos) & Prolongamento do som \\
\hline Fala (negrito) & Ênfase em som \\
\hline Fala (maiúscula) & $\begin{array}{l}\text { Som em volume mais alto do que os do } \\
\text { entorno }\end{array}$ \\
\hline [ ] colchetes & $\begin{array}{l}\text { Fala sobreposta (mais de um interlocutor } \\
\text { falando ao mesmo tempo) }\end{array}$ \\
\hline${ }^{\circ}$ fala ${ }^{\circ}$ & Som em volume mais baixo \\
\hline$>>_{\text {fala< }}$ & Fala acelerada \\
\hline \multirow{4}{}{ fala> } & Fala desacelerada \\
\hline$(\quad$ ) parênteses vazios & Segmento de fala que não pôde ser transcrito \\
\hline$(2,5)$ números entre parênteses & Medida de silêncio \\
\hline$=($ sinais de igual) & Elocuções contíguas \\
\hline
\end{tabular}

